\title{
Designing the eatwell week: the application of eatwell plate advice to weekly food intake
}

\author{
Wilma S Leslie ${ }^{1, *}$, Fiona Comrie ${ }^{2}$, Michael EJ Lean ${ }^{1}$ and Catherine R Hankey ${ }^{1}$ \\ 'Human Nutrition, School of Medicine - GRI Campus, University of Glasgow, Room 22, 4th Floor, Walton \\ Building, Glasgow Royal Infirmary, 84 Castle Street, Glasgow G4 OSF, UK: ${ }^{2}$ Food Standards Agency in \\ Scotland, Aberdeen, UK
}

Submitted 20 December 2011: Final revision received 30 July 2012: Accepted 3 August 2012: First published online 25 September 2012

\begin{abstract}
Objective: To develop a menu and resource to illustrate to consumers and health professionals what a healthy balanced diet looks like over the course of a week. Design: Development and analysis of an illustrative $7 \mathrm{~d}$ 'eatwell week' menu to meet current UK recommendations for nutrients with a Dietary Reference Value, with a daily energy base of $8368 \mathrm{~kJ}$ ( $2000 \mathrm{kcal}$ ). Foods were selected using market research data on meals and snacks commonly consumed by UK adults. Analysis used the food composition data set from year 1 (2008) of the UK National Diet and Nutrition Survey rolling programme. The eatwell week menu was developed using an iterative process of nutritional analysis with adjustments made to portion sizes and the inclusion/ exclusion of foods in order to achieve the target macronutrient composition.

Results: Three main meals and two snacks were presented as interchangeable within the weekdays and two weekend days to achieve adult food and nutrient recommendations. Main meals were based on potatoes, rice or pasta with fish (two meals; one oily), red meat (two meals), poultry or vegetarian accompaniments. The 5-a-day target for fruit and vegetables (range 5-6.7 portions) was achieved daily. Mean salt content was below recommended maximum levels $(<6 \mathrm{~g} / \mathrm{d})$. All key macro- and micronutrient values were achieved.

Conclusions: Affordable foods, and those widely consumed by British adults, can be incorporated within a $7 \mathrm{~d}$ healthy balanced menu. Future research should investigate the effect of using the eatwell week on adults' dietary habits and health-related outcomes.
\end{abstract}

Diet quality has a vital role in the health of people of all ages and to prevent chronic disease ${ }^{(1)}$. Over the last few decades the consumption of high-fat, high-energy foods has become more frequent by the populations of many countries, including Scotland and the UK as a whole. Lifestyles are also more sedentary, with adverse effects for cardiovascular and cancer risks and for overweight and obesity. Consequently chronic non-communicable diseases are the major causes of disability and premature death ${ }^{(1)}$. There has been long-standing commitment from successive UK governments to improve the diet of the population and many strategies/policies have been established ${ }^{(2-5)}$, but obesity prevalence continues to increase.

In the UK the principal public health tool for communicating information about eating for health is the eatwell plate, a pictorial representation of how different foods contribute towards a healthy balanced $\operatorname{diet}^{(6)}$. However, consumers still appear to have difficulty putting this into practice. In Scotland little improvement was observed in food and nutrient intakes between 1996 and $2005^{(7)}$. Data to 2009 showed small reductions in the percentage of energy from saturated fat and non-milk extrinsic sugars; however, both still exceed dietary targets ${ }^{(8)}$. National survey data (from the National Diet and Nutrition Survey, NDNS) show that, while saturated fat intakes have fallen a little in the UK, they remain higher than the recommended level of $11 \%$ total energy. Two-thirds of adults do not achieve the 5-a-day target for fruit and vegetables; and oily fish consumption does not meet the recommended one portion per week ${ }^{(9)}$.

There are significant inequalities in health risks within the UK which are related to underlying social inequalities and are partly mediated by diet composition and food choices. Surveillance from 2001 to 2006 shows that, in Scotland, the most deprived quintile of the population consumed significantly less fruit and vegetables than those in the least deprived quintile. Consumption of brown/wholemeal bread, breakfast cereals, white fish 
and oil-rich fish were significantly higher in the least deprived compared with the most deprived ${ }^{(10)}$.

Provision of more structured quantitative guidance may enable individuals to put the pictorial eatwell plate information into practice. To demonstrate to consumers, health professionals and policy makers how public health nutrition advice could be applied to weekly food intake and assist individuals in planning their own meals, the Food Standards Agency (FSA) in Scotland commissioned the development of an eatwell week resource. The resource was designed to present a practical example of a $7 \mathrm{~d}$ menu which meets UK Dietary References Values (DRV) and dietary targets, as well as providing supplementary advice to aid the implementation of the healthy balanced diet.

\section{Methods}

\section{Design and nutritional composition}

Data on meals and snacks commonly consumed by UK adults (aged 16 years and above) were provided by Taylor Nelson Sofres (TNS), a leading market research group. The data were derived from an ongoing TNS survey called 'Worldpanel Usage'. The survey sample is representative of the mainland Great Britain population by age and sex, and is benchmarked against the 2001 census, which included children and adults. All socio-economic groups are included but the sample is not recruited to be representative by this demographic. The sample included 11000 individuals, who completed an intake diary for 2 weeks every 6 months, providing consumption records from a repeat population of 22000 individuals per annum. These data (Table 1) guided the choice of the meals and snacks within the $7 \mathrm{~d}$ eatwell week menu.

The eatwell week was designed using the nutritional needs of normal-weight adult women with light physical activity patterns $(\sim 8368 \mathrm{~kJ}(2000 \mathrm{kcal}))^{(11)}$. The meals within the week were interchangeable to allow individual consumers a 'mix and match' approach which would build up the week's nutrient intakes in slightly different ways. However, all foods in the menu must be consumed to achieve energy and nutrient requirements over the course of the week. The eatwell week menu was not planned to provide examples for children, or for vegetarian, vegan or ethnic eating patterns.

The eatwell week menu was based on current UK nutrient DRV and was required to meet: current DRV for energy and macronutrients ${ }^{(11)}$; key micronutrient recommendations for vitamins such as folate and vitamin $\mathrm{C}$ and minerals such as $\mathrm{Fe}$ and $\mathrm{Ca}$; and the Scientific Advisory Committee on Nutrition (SACN) recommendation on cooked red and processed meat consumption $(\leq 70 \mathrm{~g} / \mathrm{d})^{(12)}$. It was also required to comply with portion advice on fruit and vegetables (5-a-day) and fish (two portions per week, one of which should be oily fish), and not exceed the maximum recommended salt intake $(6 \mathrm{~g} / \mathrm{d})^{(13)}$.
Energy provision was based on the Estimated Average Requirement (EAR) of adult women (aged 19-50 years) with a physical activity level of $1 \cdot 4$, which was $8117 \mathrm{~kJ} / \mathrm{d}$ $(1940 \mathrm{kcal} / \mathrm{d})^{(11)}$. Recently, SACN published new dietary recommendations for energy which superseded the 1991 EAR for adult women ( $>19$ years), increasing it to $8698 \mathrm{~kJ} / \mathrm{d}(2079 \mathrm{kcal} / \mathrm{d})^{(14)}$. However, public health advice remains that population energy intake should not increase, since around two-thirds of the population (UK and Scotland) are overweight or obese ${ }^{(15)}$.

For vitamins and minerals where the Reference Nutrient Intake (RNI) was different for males and females, the higher RNI was achieved by the eatwell week. Energy intake, proportion of energy from macronutrients and micronutrient intakes were averaged over the course of one week, rather than achieving recommendations on a daily basis. Achievement of energy and nutrient balance over the course of the week demonstrated the key principle of the eatwell week and allowed greater flexibility and variety for consumers. The nutrient content of the eatwell week menu was intended to sit close to the limits of the DRV, so that changes for individuals from their actual diets towards a healthy balanced diet would not be too demanding for consumers, and thus more likely to be achieved.

\section{Portion sizes}

Serving amounts for the eatwell week were guided by the FSA Food Portion Sizes book ${ }^{(16)}$. However, the portion sizes selected for the eatwell week are also based on convenient household measures and common serving sizes.

\section{Dietary analysis}

Analysis of the of the eatwell week menu was carried out in Microsoft ${ }^{\circledR}$ Excel (Microsoft Office SP, 2003) and used the nutrient databank from year 1 of the NDNS 2008-2011 rolling programme. The databank contains over 5000 foods and drinks, including recipes, data obtained from food manufacturers and nutritional information from food labels.

Codes for the foods comprising the draft eatwell week were identified in the NDNS database, reviewed by the project reference group and a consensus reached on the codes to be used in the analysis. An Excel database was compiled comprising the agreed foods and codes with nutrient values for the $7 \mathrm{~d}$ of the menu.

The eatwell week menu was developed using an iterative process of nutritional analysis with adjustments made to portion sizes and the inclusion/exclusion of foods in order to achieve the target macronutrient composition. Analysis of recipes included adjustment for cooking losses of macronutrients and vitamins using data and equations available in McCance \& Widdowson's The Composition of Foods ${ }^{(17)}$. Calculation of the fruit and vegetable content of the eatwell week menu included the content of composite recipe dishes. Serving sizes of recipes were adjusted to reflect logical servings, i.e. half or quarter of the cooked weight of the recipe. 
Table 1 Summary of top meal choices according to Taylor Nelson Sofres 'Worldpanel Usage' survey data

\begin{tabular}{|c|c|}
\hline Meal occasion & Ranking of popular meals (2009) \\
\hline Breakfast & $\begin{array}{l}\text { 1. Breakfast cereal }(63 \cdot 8 \%) \\
\text { Most popular cereal types specified: porridge }(12 \cdot 5 \%) \text {, Weetabix }(8 \cdot 0 \%) \text {, cornflakes }(8 \cdot 0 \%) \\
\text { 2. Toast }(23 \cdot 6 \%) \\
\text { Bread types specified: white bread }(29 \%) \text {, wholemeal }(17 \%) \\
\text { 3. Sandwiches }(4 \cdot 0 \%) \\
\text { Most popular fillings specified: bacon }(30 \%) \text {, egg }(10 \%) \text {, cheese }(7 \%) \text {, ham }(2 \%) \text {, tuna }(<1 \%) \\
\text { 4. All-day breakfast }(3 \cdot 4 \%) \\
\text { 5. Egg on toast }(2 \cdot 6 \%) \\
\text { 6. Bacon sandwiches }(1 \cdot 4 \%)+\text { (additional to sandwich category/some overlap with plated meals) } \\
\text { 7. Cheese on toast }(0 \cdot 8 \%)\end{array}$ \\
\hline Mid-morning snack & $\begin{array}{l}\text { Total biscuits }(30 \cdot 4 \%) \text {, fruit }(29 \cdot 8 \%) \text {, bread \& rolls }(10 \cdot 2 \%) \text {, breakfast cereals }(6 \cdot 1 \%) \text {, eggs }(1 \cdot 9 \%) \text {, } \\
\text { bacon }(1.6 \%)\end{array}$ \\
\hline Lunch & $\begin{array}{l}\text { 1. Sandwiches various }(37 \cdot 3 \%) \\
\text { Most popular fillings specified: cheese }(28 \%) \text {, ham }(24 \%) \text {, bacon }(6 \%) \text {, egg }(5 \%) \text {, tuna }(4 \%) \\
\text { Most popular bread type: white }(27 \%) \text {, wholemeal }(18 \%) \\
\text { 2. Soup }(15 \cdot 0 \%) \\
\text { Most popular soup varieties specified: tomato }(24 \%) \text {, homemade, unspecified variety }(22 \%) \text {, } \\
\text { vegetable }(21 \%) \\
\text { 3. Roast meat meal (including vegetables and potatoes) }(8 \cdot 7 \%) \\
\text { 4. Cheese sandwiches }(7 \cdot 4 \%) \text { (some overlap with total sandwiches) } \\
\text { 5. Ham sandwiches }(6 \cdot 6 \%) \text { (some overlap with total sandwiches) } \\
\text { 6. Toast alone }(6 \cdot 4 \%) \\
\text { 7. Pies/pastries/puddings }(6 \cdot 0 \%) \\
\text { 8. Cheese on toast }(5 \cdot 4 \%) \\
\text { 9. Roast chicken }(3 \cdot 5 \%) \text { (some overlap with total roast meat meal) } \\
\text { 10. Tomato soup }(3 \cdot 3 \%)\end{array}$ \\
\hline Mid-afternoon & Total snack foods $(76 \cdot 8 \%)$, crisps, nuts \& snacks $(15 \cdot 4 \%)$ \\
\hline Snack & $\begin{array}{l}\text { Total biscuits }(33 \cdot 6 \%) \text {, sweet biscuits }(19 \cdot 4 \%) \text {, chocolate biscuits }(5 \cdot 0 \%) \\
\text { Fresh medium fruits }(25 \cdot 3 \%) \text {, fresh soft fruits }(7 \cdot 3 \%) \\
\text { Cakes, tarts \& pastries }(20 \cdot 9 \%) \\
\text { Confectionery (total) }(14 \cdot 2 \%) \\
\text { Total desserts }(12 \cdot 9 \%) \text {, ice cream }(1 \cdot 4 \%)\end{array}$ \\
\hline Evening meal & $\begin{array}{l}\text { 1. Pizza }(8 \cdot 5 \%) \\
\text { 2. Sandwiches }(8 \cdot 2 \%) \\
\text { 3. Fish and chips }(6 \cdot 8 \%) \\
\text { 4. Sausages with boiled or mashed potatoes }(6 \cdot 8 \%) \\
\text { 5. Fish with boiled potatoes }(4 \cdot 6 \%) \\
\text { 6. Curry }(4 \cdot 1 \%) \\
\text { 7. Stews/casseroles }(3.9 \%) \\
\text { 8. Spaghetti bolognaise }(3.5 \%) \\
\text { 9. Traditional ready meals }(3.3 \%) \\
\text { 10. Burgers and grill steaks }(3.3 \%)\end{array}$ \\
\hline Evening snack & $\begin{array}{l}\text { Crisps nuts \& snacks }(17 \%) \text {, total desserts }(15 \cdot 2 \%) \text {, yoghurts \& cold desserts }(5 \cdot 2 \%) \text {, ice cream \& } \\
\text { mousse }(0 \cdot 8 \%) \text {, confectionery (total) }(14 \cdot 4 \%) \text {, cheese (excl. cheddar) }(6 \cdot 1 \%) \text {, plain/savoury } \\
\text { biscuits }(4 \cdot 8 \%) \text {, total sandwiches }(4 \cdot 4 \%)\end{array}$ \\
\hline
\end{tabular}

*Some overlap with total sandwiches.

tSome overlap with total roast meat meal.

Fruit juice and pulses (including baked beans) were included in the calculation up to a maximum of one portion per day each. Four commonly eaten fruits (apples, bananas, oranges and grapes) were used for the purpose of analysis, with advice that any other variety could be interchanged. Once macronutrient composition was achieved, micronutrient content was checked against RNI. Any shortfalls in micronutrient provision would be addressed by adjustment of either portion size or food type.

\section{Additional considerations}

The eatwell week menu was accompanied by supplementary information to explain how the resource could be used and provided additional healthy eating and food safety advice and information, for example on salt intake, red meat consumption and basic food storage and preparation.
As there are apparent inequalities in diet between deprived and less deprived quintiles of the population ${ }^{(10)}$, it was considered important that meals and snacks included in the eatwell week menu should be affordable for those on low incomes and to require only basic skills in cooking/interest in food choice. For example, to avoid food waste, limited types of perishable food such fruit and vegetables were provided in the menu. Frozen and tinned vegetables were included as well as fresh, and while types of fruit were suggested in the eatwell week menu, it was intended that users would choose which fruits to consume depending on their preference, cost and availability. Less expensive meats were used and advice was given on using and storing leftovers.

Advice was included on safe food storage and the appropriate use of leftovers from main meals. Advice was 
also provided to aid the exchange of nutritionally equivalent foods within the food groups, i.e. suggested variations for evening meals by changing the protein source or carbohydrate used.

Further supplementary information on shopping/ planning/storing food effectively, using food labels (in particular, the FSA front-of-pack labelling system) and making healthier choices when eating out was included in the resource. Recipes for meals included in the eatwell week menu were provided and, where possible, were sourced from the eatwell website ${ }^{(18)}$. The provision of recipes had a twofold purpose: (i) to provide healthier versions of meals/foods which may otherwise have been purchased as convenience meals; and (ii) to encourage consumers to cook meals from their raw ingredients.

Information was included on how to increase or decrease energy intake depending on gender and level of physical activity. Calculations were completed to identify which foods could be included or excluded from the eatwell week while still maintaining micronutrient provision and the correct proportions of energy from macronutrients, without exceeding maximum salt intake recommendations. These calculations illustrate the eatwell week menu $\pm 2092 \mathrm{~kJ}$ ( $500 \mathrm{kcal})$.

Males or physically active women who may require to eat more were advised to: eat more wholegrain, lowsugar breakfast cereal; have a larger portion of main meals including extra rice, pasta or potatoes; have extra fruit and more vegetables with meals; and increase the amount of filling in baked potatoes and sandwiches. Those wishing to eat less were advised to: exclude desserts, chocolates, biscuits and crisps; have either breakfast cereal or toast at breakfast; and have main meals without extra bread.

The format of the resource was an A5-sized laminated booklet with a continuous spiral binding. The booklet included seven pages divided into four sections (one each for breakfast, lunch, evening meal and snacks). This design allowed meal options for each day to be interchangeable, thus increasing the flexibility of the eatwell week. The front of each of the four sections showed a picture of the suggested meal with text alongside detailing the content of the meal. The reverse of each section gave the recipe ingredients, more general tips relevant to that particular meal, or meal alternatives.

\section{Results}

\section{Existing food consumption data}

According to TNS data, cereal and toast were the most common breakfast food items; sandwiches and soups the most popular lunchtime meals (Table 1). Popular evening meals were pasta dishes, followed by 'roast dinner'. Differences were seen in the choices of snacks depending on the time of day consumed. The most popular morning snacks were biscuits and fruit, whereas crisps, nuts and snacks, confectionery and cheese were the most favoured afternoon and evening snacks. Overall, the most popular snack item was biscuits.

\section{Мепu}

The menu developed comprised three main meals (breakfast, lunch and evening meal) plus one or more foods which could be consumed as snacks or as additions to meals. Two cooked breakfasts were included, which could be prepared when there was more time available. The remaining breakfasts comprised toast with either wholegrain breakfast cereals or porridge (Table 2). Lunches comprised mainly sandwiches and soups, reflecting the TNS data. A variety of evening meals were included. Red meat was included in the evening meal on two days and two portions of fish were incorporated, one white and one oily, to meet current dietary targets.

\section{Dietary analysis}

\section{Energy and macronutrients}

Mean energy provision was $8577 \mathrm{~kJ}$ (2050 kcal), close to the target of $8368 \mathrm{~kJ}$ ( $2000 \mathrm{kcal} / \mathrm{d}$; Table 3). Daily energy intake ranged from 7670 to $9126 \mathrm{~kJ} / \mathrm{d}$ (1833 to $2181 \mathrm{kcal} / \mathrm{d}$; Table 3). Mean percentage of energy from fat was lower than the DRV at $34 \%$, as was mean percentage of energy from saturated fat (10\%) and non-milk extrinsic sugars (9\%). Saturated fat and total fat content varied throughout the week, but only exceeded the maximum DRV (11\%) on one day of the week by $1.5 \%$. Percentage of energy from carbohydrate exceeded the DRV (50\%) by around $4 \%$ on two days of the week.

All micronutrient intakes were achieved, apart from Se (Table 3). For at least eight micronutrients (Fe, Zn, vitamin $\mathrm{B}_{12}$, vitamin $\mathrm{B}_{6}$, riboflavin, niacin and vitamin $\mathrm{C}$ ) provision varied by as much as $50 \%$ between days, depending on the foods suggested for each individual day (Table 3).

Mean salt content was kept below the maximum recommended intake (Table 3 ). As with other nutrients, salt content varied daily and exceeded the RNI by about $1 \mathrm{~g}$ on two days of the week (Table 3).

\section{Food group targets}

The target for fruit and vegetables of 5-a-day ( $400 \mathrm{~g}$ ) was achieved on each day. Mean daily content was $544 \mathrm{~g}$ (range 434-720 g) and included visible portions of fruit and vegetables and those contained in composite dishes. The SACN recommendation of no more than $70 \mathrm{~g}$ of cooked red meat daily was achieved, as was the dietary target for fish intake.

\section{Discussion}

Resources such as the eatwell plate and other international models aim to make healthy eating simpler to grasp and to assist in the prevention and management of 


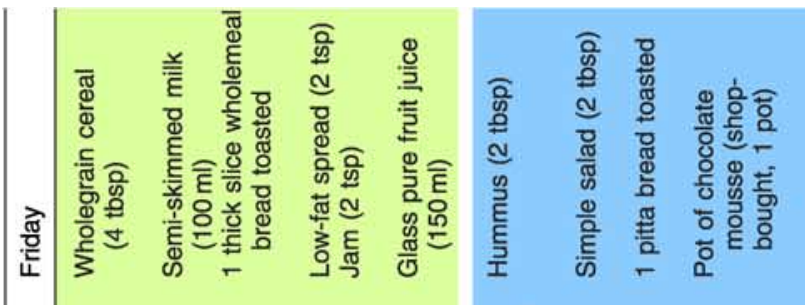

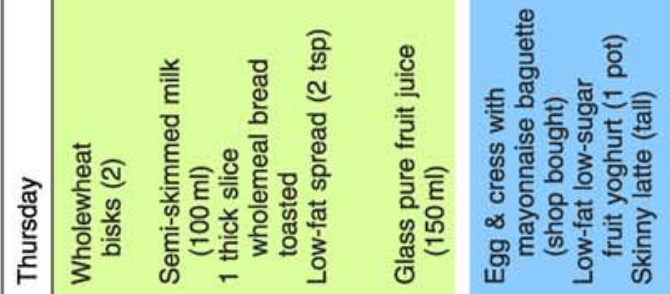

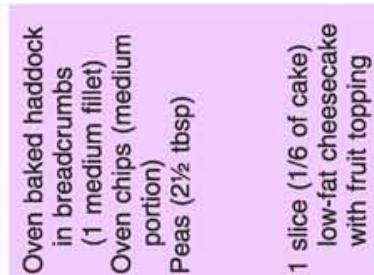

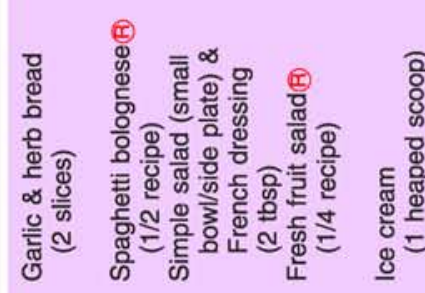

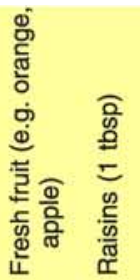

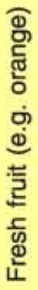

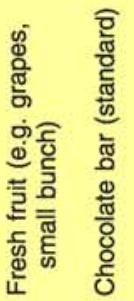

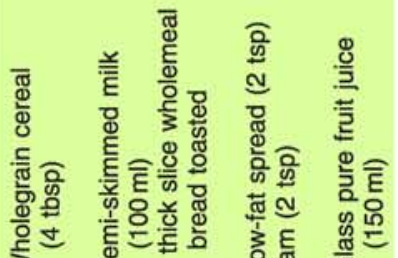
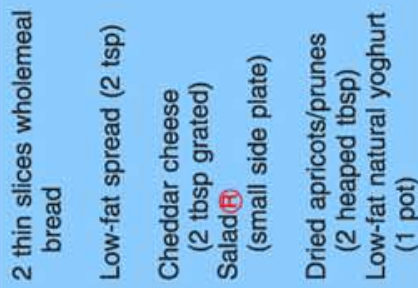

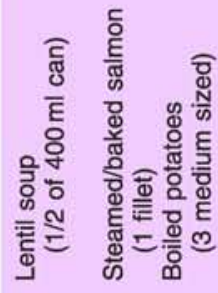

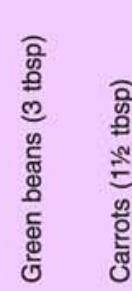

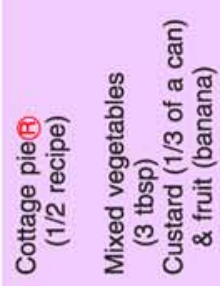

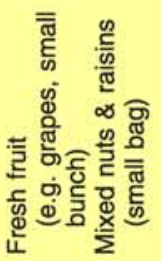
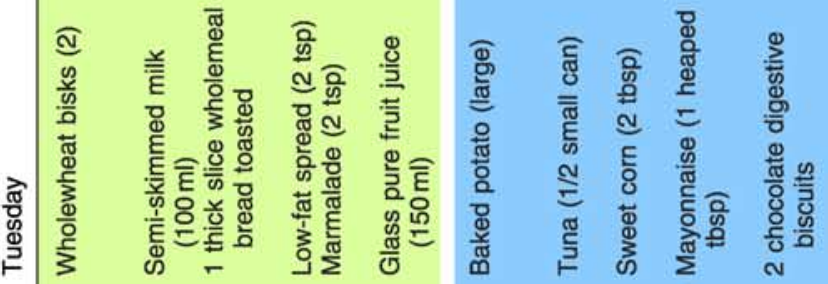

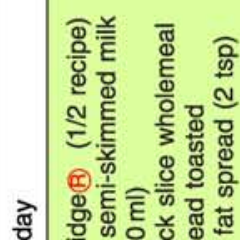

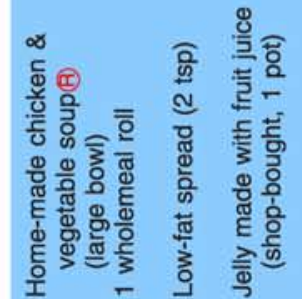

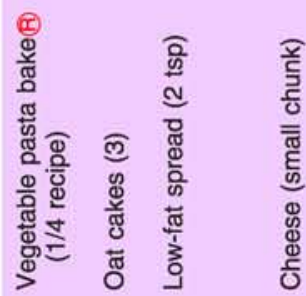
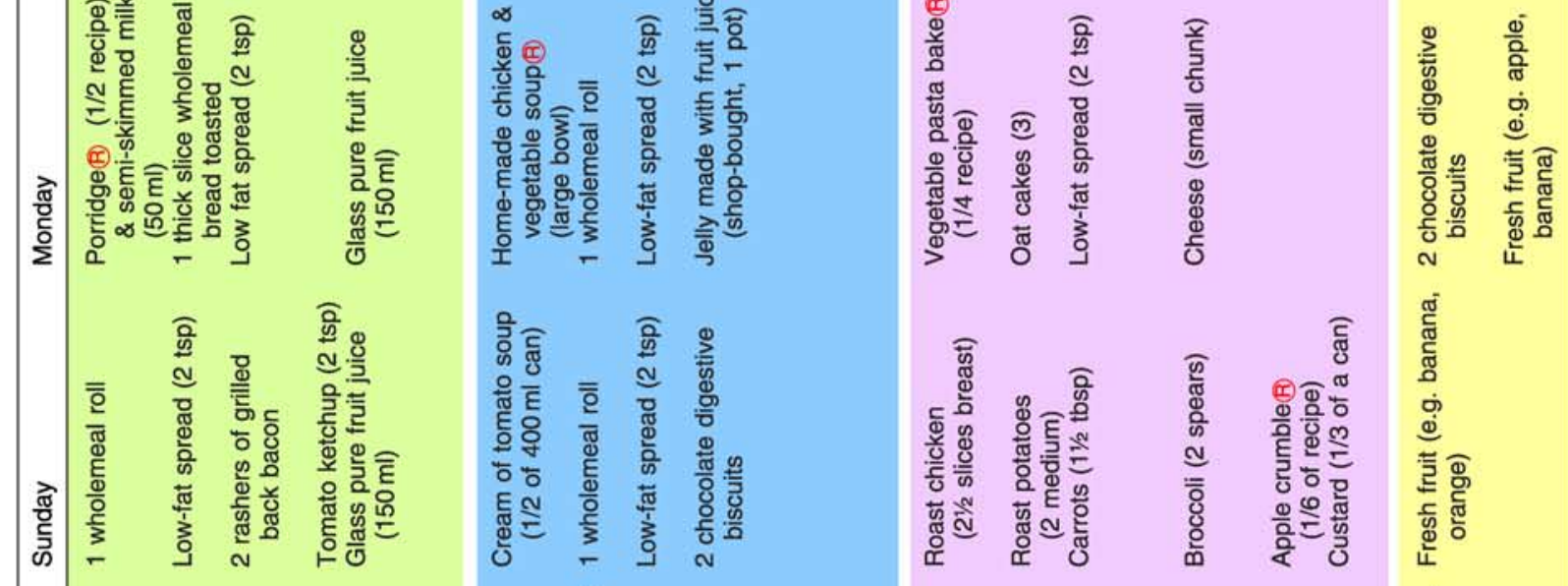

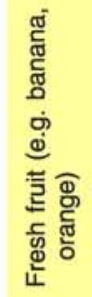

J

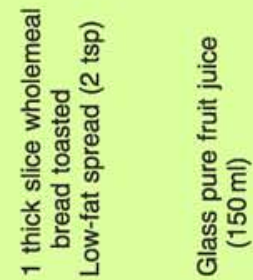
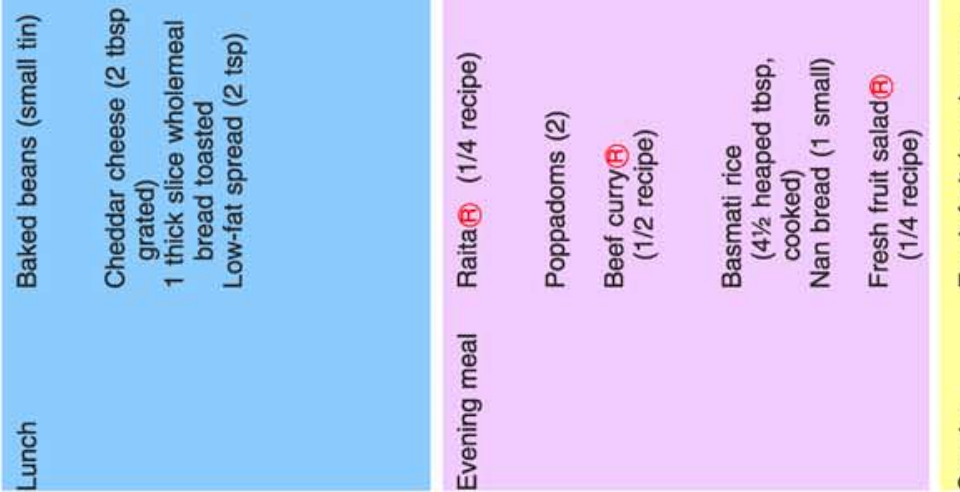
Table 3 Target and actual (mean and range) energy, macronutrient and micronutrient composition of the eatwell week menu

\begin{tabular}{|c|c|c|c|}
\hline \multirow[b]{2}{*}{ Nutrient } & \multirow[b]{2}{*}{ Target } & \multicolumn{2}{|c|}{ eatwell week } \\
\hline & & Mean & Range \\
\hline \multicolumn{4}{|l|}{ Energy* } \\
\hline $\mathrm{kJ}$ & $\sim 8368$ & 8577 & 7670-9126 \\
\hline kcal & 2000 & 2050 & $1833-2181$ \\
\hline Total fat (\% of energy) $\dagger$ & 35 & 33.5 & $31 \cdot 0-37 \cdot 0$ \\
\hline Saturated fat $(\%$ of energy) $\dagger$ & 11 & $9 \cdot 8$ & $7 \cdot 1-12 \cdot 5$ \\
\hline Carbohydrate (\% of energy) $†$ & 50 & $51 \cdot 0$ & $47 \cdot 5-55 \cdot 6$ \\
\hline NMES $(\%$ of energy) $\dagger$ & $\leq 11$ & $8 \cdot 7$ & $4 \cdot 3-13 \cdot 4$ \\
\hline NSP (fibre) (g)† & 18 & $23 \cdot 7$ & $20 \cdot 0-28 \cdot 5$ \\
\hline Protein (\% of energy) $\ddagger$ & 15 & 16 & $13 \cdot 1-18 \cdot 4$ \\
\hline Salt $(g) \S$ & 6 & $5 \cdot 5$ & $3 \cdot 4-7 \cdot 1$ \\
\hline Vitamin $A(\mu \mathrm{g}) \|$ & 600 & 1022 & $655 \cdot 0-1188 \cdot 3$ \\
\hline Thiamin (mg)\| & $1 \cdot 0$ & $2 \cdot 1$ & $1 \cdot 4-2 \cdot 5$ \\
\hline Riboflavin (mg)\| & $1 \cdot 3$ & 1.9 & $0 \cdot 8-3 \cdot 0$ \\
\hline Niacin (mg) $\|$ & 17 & $24 \cdot 8$ & $12 \cdot 9-35 \cdot 6$ \\
\hline Vitamin C (mg)\| & 40 & 190 & $108 \cdot 6-264 \cdot 7$ \\
\hline Vitamin $B_{6}(\mathrm{mg}) \|$ & $1 \cdot 4$ & $2 \cdot 6$ & $1 \cdot 8-3 \cdot 6$ \\
\hline $\operatorname{Vitamin} \mathrm{B}_{12}(\mu \mathrm{g}) \|$ & 1.5 & $4 \cdot 7$ & $1 \cdot 6-7 \cdot 0$ \\
\hline Folate $(\mu \mathrm{g}) \|$ & 200 & 361 & $229 \cdot 5-420 \cdot 3$ \\
\hline $\mathrm{K}(\mathrm{mg}) \|$ & 3500 & 4199 & $3739 \cdot 5-5101 \cdot 4$ \\
\hline $\mathrm{Ca}(\mathrm{mg}) \|$ & 700 & 924 & $612 \cdot 4-1490 \cdot 3$ \\
\hline $\operatorname{Mg}(\mathrm{mg}) \|$ & 300 & 358 & $301 \cdot 3-422 \cdot 4$ \\
\hline$P(m g) \|$ & 550 & 1445 & $1110 \cdot 8-1715 \cdot 7$ \\
\hline $\mathrm{Fe}(\mathrm{mg}) \boldsymbol{\top}$ & $14 \cdot 8$ & $15 \cdot 4$ & $8 \cdot 7-20 \cdot 7$ \\
\hline $\mathrm{Zn}(\mathrm{mg}) \|$ & $9 \cdot 5$ & $9 \cdot 2$ & $7 \cdot 1-14 \cdot 1$ \\
\hline Se $(\mu \mathrm{g}) \|$ & 75 & $53 \cdot 0$ & $36 \cdot 1-83 \cdot 7$ \\
\hline
\end{tabular}

NMES, non-milk extrinsic sugars; RNI, Recommended Nutrient Intake; DRV, Dietary Reference Value.

*Target daily energy intake.

tDRV for adults.

¥Protein intakes average $16 \%$ of energy which exceeds the RNI. However, protein intakes should not exceed twice the RNI $(45 \cdot 0 \mathrm{~g}$ for females aged $19-50$ years).

\$Based on the Scientific Advisory Committee on Nutrition recommendation.

$\| \mathrm{RNI}$ for males aged $19-50$ years.

ๆRNI for females aged $19-50$ years.

overweight and obesity. However, recent dietary monitoring has confirmed that the UK population currently fails to achieve dietary recommendations, suggesting that difficulties exist in understanding and applying the guidance set out by these models. Provision of additional tools to help individuals interpret and put into practice healthy eating dietary advice is pertinent and supports the UK and Scottish governments' public health policies.

\section{Addressing barriers to bealthy eating}

At an individual level, many barriers are cited that prevent the implementation of healthy eating. Those most frequently reported are cost, cooking skills, hard to change existing eating habits and difficulties in giving up preferred foods ${ }^{(19)}$. The use of TNS data to guide the development of the eatwell week menu was therefore important to ensure the appropriateness of the menu for the UK population. It was hoped that including foods/meals that were familiar and commonly consumed in the UK would improve user acceptability of the resource, thus minimising some of the barriers to change. Use of familiar foods also demonstrated that a healthy diet need not completely exclude foods that are liked and enjoyed such as those high in fat and or sugar.
TNS data may also give some indication of affordability, the inference being if they are commonly consumed they are likely to be affordable. The eatwell week menu includes similar foods to a menu designed to meet the UK DRV and addresses sustainability issues by reducing greenhouse gas emissions associated with the menu ${ }^{(20)}$. The similarity of the menus confirms the acceptability of the foods indicated by TNS data.

\section{Constraints imposed by dietary reference values}

Use of the NDNS nutrient databank ensured that analysis of the week was as accurate and current as possible in terms of nutrient content. The main limiting factor in the design of the menu was ensuring that salt intake did not exceed an average of $6 \mathrm{~g} / \mathrm{d}$ and this was achieved. The initial aim was to set salt intake at no more than $5 \mathrm{~g} / \mathrm{d}$, as the SACN recommendation (no more than $6 \mathrm{~g}$ salt/d) is based on $5 \mathrm{~g} / \mathrm{d}$ for adult women and $7 \mathrm{~g} / \mathrm{d}$ for adult men ${ }^{(13)}$. However, the $6 \mathrm{~g} / \mathrm{d}$ population recommendation is challenging as in Scotland men consume about $10 \mathrm{~g}$ salt/d and women about $8 \mathrm{~g}$ salt $/ \mathrm{d}^{(21)}$.

The eatwell week menu should lend itself to use within families; however, salt intake provided a further challenge 
when the menu was checked to see if it was suitable for children. By proportionately decreasing energy intake, the salt content of the eatwell week is decreased. However, the SACN salt target for children younger than 7 years $(<3 \mathrm{~g} / \mathrm{d})^{(12)}$ is lower than the proportionate level achieved in the eatwell week $(4 \cdot 1 \mathrm{~g} / \mathrm{d})$. Thus for use with younger children, certain salty foods would have to be excluded. One solution could be to reduce further the salt content of the menu, so that it is suitable for younger children and can be used by more families; this may however reduce the acceptability of the menu for many adults. It should be considered that following the eatwell week menu may, for many families, facilitate an improvement in dietary intake and a lowering of usual salt intake and there may be an opportunity to develop advice for families on choosing lower salt foods.

The menu was based on the energy requirement of women aged 19-60 years. Average energy intakes for women aged 19-64 years are currently reported as below the EAR for food energy, at $6853 \mathrm{~kJ} / \mathrm{d}(1638 \mathrm{kcal} / \mathrm{d})^{(9)}$. However this is unlikely, given the rising prevalence of overweight and obesity, as for many women this level of intake would result in weight loss. Such data are likely to reflect under-reporting, widely recognised in dietary surveys, and energy intakes are in reality greater than this. New draft EAR for energy for the UK population calculates a value of about $8368 / \mathrm{d}(2000 \mathrm{kcal} / \mathrm{d})$ for women aged 19-49 years ${ }^{(14)}$. These figures aim for weight maintenance at a BMI of $22 \cdot 5 \mathrm{~kg} / \mathrm{m}^{2}$. For those with a higher BMI, energy requirements will be more, and the requirements of men are about $15 \%$ greater. The eatwell week menu was not designed primarily as an aid to weight loss, but if followed by overweight or obese individuals, it would, in time, lead to weight loss towards BMI $22 \cdot 5 \mathrm{~kg} / \mathrm{m}^{2}$.

Initially in the process of designing the menu, the fat contribution to total energy provision was too low, as a result of including lower-fat food options (spreads, milk and other dairy products) and a number of iterations were required to correct this. 'Standard' food options were selected, including standard mayonnaise, crisps and garlic bread, rather than lower-fat options, to maintain total fat intake at the limit of the DRV (no more than 35\% energy from fat). It was possible to include these options due to the small amount of foods high in fat and/or sugar in the menu overall.

Micronutrient contents varied considerably between days and this was inevitable given the variety of meals presented, which were based on TNS data. Variations were the result of foods or food groups that were rich in particular micronutrients, e.g. red meat $(\mathrm{Fe})$ and citrus fruits (vitamin C), and did not result from the inclusion of specific micronutrient-rich foods in order to address nutrient shortfalls. The eatwell week menu achieved all of the relevant nutrient intake targets with the exception of Se. However, Se intake does exceed the Lower Reference Nutrient Intake for both male and female adults $(40 \mu \mathrm{g} / \mathrm{d})$.
Specific foods, i.e. Brazil nuts, could have been added to the menu to address this deficit; however, it would not have been appropriate to include uncommonly consumed foods in the eatwell week.

The eatwell week menu illustrated fruit and vegetable provision of at least five daily portions. In the UK, average intake of fruit and vegetables has been reported as about 4 portions/d for both men and women ${ }^{(9)}$ and in Scotland average consumption is reported as about 3 portions $/ \mathrm{d}^{(8)}$, although potentially this difference may be due to small differences in the way fruit and vegetable intakes are calculated. Following the eatwell week menu would result in an increase in fruit and vegetable consumption for many people. It was felt that including much more than five portions daily in the eatwell week menu would seem unachievable, and therefore off-putting, to potential users.

\section{Limitations of the menu}

The menu was not designed to meet the needs of those from ethnic minority backgrounds. Similarly, the eatwell week menu does not address the dietary requirements of those who exclude all or some animal products from their diet or those with specific dietary requirements. However, the resource does provide suggestions for non-meat alternatives to some of the meals included and this may be beneficial to individuals trying to follow a vegetarian diet. Specific themed alternative eatwell week menus could be designed in the future.

\section{Conclusions}

We have demonstrated that it is possible to develop a menu, incorporating foods that are popular and widely consumed by British adults, which meets dietary recommendations and targets and is not dependent on any single food item, or any unusual or expensive pattern of eating, to meet nutrient targets. The use of popular, familiar foods aimed to address the barrier of acceptability and may also make changing dietary behaviour less daunting for consumers. The main limiting factor in the menu design was ensuring that the recommendations on salt intake were not exceeded. Although mean salt provision was within these limits, the menu is not suitable for younger children ( $<7$ years).

Many healthy eating resources are available to the public and health professionals and it was important to garner the opinions of these groups to allow focused objective assessment of the menu and finalised resource, in order to increase its acceptability and ultimately uptake and effective implementation. Focus group testing of the draft resource was undertaken and will be reported separately.

The eatwell week has been successfully designed as a resource to support implementation of the principles of the eatwell plate. It supports Government priorities and policies for health including obesity and weight 
management. It offers a route to reduce health inequalities related to diet composition and should be broadly and culturally acceptable. The eatwell week resource has a place among other policies and initiatives to improve dietary health; however, further development and evidence for effectiveness are required before making the resource available to health professionals and consumers.

\section{Acknowledgements}

Source of funding: The eatwell week project (S14048/ FS424017) was funded by FSA in Scotland. Conflicts of interest: F.C. is employed by FSA in Scotland. The remaining authors declare no conflict of interest. Authors' contributions: The study was designed by W.S.L., M.E.J.L. and C.R.H. W.S.L. carried out the analyses and all authors critically reviewed the manuscript.

\section{References}

1. World Health Organization (2003) Diet, Nutrition and the Prevention of Chronic Diseases. Joint WHO/FAO Expert Consultation. WHO Technical Report Series no. 916. Geneva: WHO.

2. The Scottish Government (1996) Eating for Health: A Diet Action Plan for Scotland. London: HMSO.

3. HM Government (2010) Healthy Lives, Healthy People: Our Strategy for Public Health in England. London: TSO; available at http://www.official-documents.gov.uk/document/ cm79/7985/7985.pdf

4. Department for Environment, Food and Rural Affairs (2010) Food 2030. http://sd.defra.gov.uk/2010/01/food2030/ (accessed April 2011).

5. The Scottish Government (2010) Preventing Overweight and Obesity in Scotland: A Route Map Towards Healthy Weight. http://www.scotland.gov.uk/Publications/2010/02/ 17140721/19 (accessed May 2010).

6. Food Standards Agency (2010) The eatwell plate. http:// tna.europarchive.org/20100929190231/http://www.eatwell. gov.uk/healthydiet/eatwellplate/ (accessed April 2011).

7. Lang T, Dowler E \& Hunter D (2006) Review of the Scottish Diet Action Plan: Progress and Impacts 1996-2005. Edinburgh: Health Scotland.

8. Barton KL, Wrieden WL, Armstrong J et al. (2011) Estimation of food and nutrient intakes from Expenditure and Food Survey \& Living Costs and Food Survey Data in Scotland 2001-2009. Report to the Food Standards Agency
Scotland, 31st March 2011. http://www.foodbase.org.uk// admintools/reportdocuments/418-1-1141_S14035_Monitoring_ Report_2001-2009_310311final.pdf (accessed May 2011).

9. Department of Health (2011) National Diet and Nutrition Survey: Headline results from Years 1 and 2 (combined) of the Rolling Programme, 2008/9-2009/10. http://www.dh.gov. uk/en/Publicationsandstatistics/Publications/Publications Statistics/DH_128166 (accessed July 2011).

10. Barton KL, Wrieden WL, Armstrong J et al. (2010) Estimation of Food and Nutrient Intakes from Expenditure and Food Survey Data in Scotland 2001-2006. http:// www.foodbase.org.uk//admintools/reportdocuments/418-11027_S14035_Final.pdf (accessed May 2011).

11. Department of Health (1991) Dietary Reference Values for Food, Energy and Nutrients for the United Kingdom. London: HMSO.

12. Scientific Advisory Committee on Nutrition (2010) Iron and Health. London: TSO; available at http://www.sacn. gov.uk/reports_position_statements/reports/sacn_iron_and_ health_report.html

13. Scientific Advisory Committee on Nutrition (2003) Salt and Health. London: TSO; available at http://www.sacn. gov.uk/reports_position_statements/reports/salt_and_health_ report.html

14. Scientific Advisory Committee on Nutrition (2009) Energy Requirements Draft Working Group Report. http://www. sacn.gov.uk/reports_position_statements/reports/draft_energy_ requirements_report_scientific_consultation_-november_2009. html (accessed August 2011).

15. Bromley C, Corbett J, Day J et al. (2011) Scottish Health Survey 2010 - Volume 1: Main report. http://www.scotland.gov.uk/ Publications/2011/09/27084018/0 (accessed September 2011).

16. Food Standards Agency (2002) Food Portion Sizes, 3rd ed. London: TSO.

17. Food Standards Agency (2002) McCance and Widdowson's the Composition of Foods, 6th summary ed. Cambridge: Royal Society of Chemistry.

18. Food Standards Agency (2010) Eat well, be well - Recipes. http://tna.europarchive.org/20100929190231/http://www. eatwell.gov.uk/healthydiet/recipes/ (accessed April 2011).

19. National Obesity Observatory (2011) Knowledge and attitudes to healthy eating and physical activity: what the data tell us. http://www.noo.org.uk/uploads/doc/vid_11171_ Attitudes.pdf (accessed October 2011).

20. Macdiarmid J, Kyle J, Horgan G et al. (2011) Livewell: a balance of healthy and sustainable food choices. http:// assets.wwf.org.uk/downloads/livewell_report_corrected. pdf (accessed April 2011).

21. Scottish Centre for Social Research (2011) A survey of 24 hour urinary sodium excretion in a representative sample of the Scottish population as a measure of salt intake. http:// www.foodbase.org.uk//admintools/reportdocuments/681-11229_S14047.pdf (accessed November 2011). 